\title{
Adoption of HACCP Food Safety Metasystem by Tea and Dairy Processing Firms in Sri Lanka: An Empirical Assessment on Incentives for Firms to Act
}

\author{
U. K. Jayasinghe-Mudalige ${ }^{1}$, S. M. M. Ikram ${ }^{1}$, J. M. M. Udugama ${ }^{1}$, \\ J. C. Edirisinghe ${ }^{1}$ and H. M. T. K. Herath ${ }^{1}$
}

Received : $23^{\text {rd }}$ June 2015 / Accepted : 06 ${ }^{\text {th }}$ August 2015

\begin{abstract}
The impact of individual market-based, regulatory and liability incentives on food safety responsive behaviour of firms is assessed using the Sri Lankan tea and dairy processing firms' motivation to adopt Hazard Analysis \& Critical Control Points (HACCP) food safety metasystem as the case. A series of face-to-face interviews were conducted with the manager responsible for food quality assurance in the firm, supported by a validated structured questionnaire and a site inspection, between April and September 2010 to collect data from tea $(n=32)$ and dairy $(n=34)$ processing firms operate in six provinces. A comprehensive Structural Equation Model was developed using the "Analysis of Moment Structures" statistical package to elicit the effect of nine individual incentives on firms" decision to adopt HACCP. Further an Incentive-Related Index reflecting the strength of each incentive was derived. The outcome of analysis suggests that "Reputation" and "Anticipate government regulation" possess the greatest impact on a firm's food safety behaviour along with "Sales and Revenue" for tea and "Liability Laws" for the dairy processing sectors. It also implies that larger firms have a greater tenacity to adopt HACCP than smaller firms and tea sector is more likely to adopt this metasystem voluntarily than the dairy sector. This creates the need for policy makers to recognize the importance of market-based incentives and the close interplay and interactions of which with regulatory incentives, and in turn, importance of development of a properly functioning regulatory and liability system and a steadfast system to inject market-based motivators such as brand equity to promote adoption of HACCP among firms.
\end{abstract}

Keywords: Agri-food processing sector in Sri Lanka, Economic incentives, Food safety and quality, $H A C C P$

\section{INTRODUCTION}

Throughout the world, there is an on-going process of reforms to the food safety controls. In part, this is in response to the emerging regulations and standards on food safety and quality and the rising demands of the food markets at the local, regional to international level. In fact, the governments as well as respective food processing industries, both in the developed and developing countries, are currently intensifying their efforts to improve the levels of food safety in response to an increasing number of food safety problems and rising consumer concerns (Henson and Traill,
2000; Veeman, 2000, Wu et al., 2012). Parallel to the reform of food safety regulations, private enterprises are themselves implementing new forms of food safety controls to act in accordance with the demands of the local and international markets and/or internal management pressures. One example is adoption of Hazard Analysis \& Critical Control Point (HACCP) food safety metasystem (Caswell et al, 1998; Mortimore and Wallace, 1998).

Like many other developing and developed countries, the agri-food processing sectors 
in Sri Lanka face an array of challenges and opportunities related to the management of food safety; with regulatory requirements in a "state of flux", laying down increasingly strict requirements on the end-product quality and the production processes, and their customers, locally and globally, demanding ever more strict food safety standards. Also, food safety controls can impose a significant economic burden on agri-food businesses that can threaten national and international competitiveness. All of these factors highlight the need for food safety controls to be effective and cost efficient. Thus, it requires a clear understanding of the underlying economic forces that induce and control food safety in the agricultural and food processing sectors (Henson, 2007, Henson and Jaffee, 2008).

There is an ongoing debate involving economists and policy-makers regarding the most effective and desirable mechanisms to achieve an appropriate level of food safety. A review of the food economics literature identifies a number of incentives and provides evidence of the potential roles played by these incentives. They have begun to recognize that food suppliers face a broad array of incentives to implement enhanced food safety controls (Bukenya and Nettles, 2007, Henson and Holt, 2000, Ollinger and Moore, 2008). According to Segerson (1999), a system of economic incentives operates broadly at two levels, i.e. market-driven versus regulatory inducements or liability legislation. Buzby et al. (2001) suggest three elements that create incentives for a food business to have enhanced food safety controls in its place, including: (1) market forces; (2) food safety laws and regulation, and (3) product liability laws.

Jayasinghe-Mudalige and Henson (2007) subdivided these three elements of a system of economic incentives further into ten hypothetical distinct incentives and suggest that the relative importance of each of these incentives to adopt enhanced food safety controls differs across different sectors in an economy and regions within a country. The literature also suggests that in many circumstances, these incentives are both inter-related and operate simultaneously (Henson and Hooker, 2001) and the controls implemented by individual businesses can, in turn, reflect the interplay between them (Henson and Northen, 1998).

Consequently, it is required that these economic incentives are managed in such a way that food safety controls, and more specifically metasystems like HACCP, are implemented in the most efficient and cost effective manner, both from the perspective of private enterprises and government. Nevertheless, to date, there is little systematic evidence available that reports the effectiveness of incentive-based marketoriented mechanisms to ensure food safety, and the findings from empirical studies based on the performance of food industries in the developing world in this respect are scarce. In light of this, the objectives of this study were of two-fold. First, to examine empirically the extent to which the individual economic incentives comprised of market and non-market forces (i.e. regulatory / legal) motivate firms operate in the agri-food processing sectors in Sri Lanka to adopt the HACCP metasystem. Next, to assess the impact of firm and market-specific characteristics on the strength of prevailing these incentives at the levels of firm to augment adoption of HACCP.

The empirical analysis was based on the firms operate in two prominent food processing industries in Sri Lanka, namely the: (1) Tea, and (2) Dairy processing firms. The selection of which for this study was on the justification of several factors. First, these two products represent two distinct agriculturebased industries, i.e. "crop" and "livestock" respectively, and cater into two different markets. For example, more than ninety percent of processed tea is exported to the international markets, where the food safety concerns are matter for everybody in the food supply chain more than ever, and as a result, the exports are 
subject to both globally and locally oriented food safety standards and regulations in various forms. In the case of dairy products, a large share of which is consumed domestically, and due to highly sensitive nature of the products, they are inherently subjected to the food safety and quality related issues. Further, these firms are scattered all over the country and play a substantial role in Sri Lankan economy in terms of their contribution to domestic production, markets, value-addition and employment etc.

\section{METHODOLOGY}

Here we present the results of first phase of a multi-stage program of research carried out on this issue. A systematic procedure was used to assess the effect of individual economic incentives on firms' decision to adopt HACCP empirically. On one hand, we need to understand the firm's level of adoption of HACCP, and the effect of individual economic incentives that can have an impact on this decision must be evaluated, on the other. The steps used to identify, and in turn, to quantify the individual incentives using the Structural Equation Modelling (SEM) techniques are explored next.

\section{Firm's Level of Adoption of HACCP}

At a given point of time, a firm can be classified into one of the four categories based on the actions taken by its management with respect to the adoption of the HACCP food safety metasystem, such that the firm: (1) has "no plan" to implement it; (2) "has a written plan" to implement it; (3) "is in the process" of implementing it, and (4) "has already adopted" it. A careful investigation into the process and records through site inspection has, therefore, become a must to determine the state of adoption.

\section{Identifying the Individual Economic Incentives}

We hypothesized that the managerial decisions on the adoption of HACCP was coupled with a system of economic incentives a firm faces, which is comprised of the market (private), regulatory (public) and liability (judiciary) incentives and is characterized by the direct and indirect "expected benefits" and "costs" to the firm arising from that decision. The nine individual incentives identified in JayasingheMudalige and Henson (2007) using a qualitative approach based on $\mathrm{N}$-Vivo statistical package and a quantitative assessment based on indexbased Logistic Ordered Regression were chosen to serve as the base of the theoretical formulation of the model. It classifies these nine incentives under three main types of economic incentives, including: market-based incentives such as (1) financial implications/cost (CST); (2) efficiency in human resources (HRE); (3) efficiency in technical procedures (TCE); (4) sales and revenue (SLR); (5) reputation (REP), and (6) commercial pressure (CPR); regulatory incentives such as (7) existing government regulation (EGR) and (8) anticipated government regulation (AGR), and Liability incentives such as (9) liability laws (LBL).

\section{Quantification of Effect of Economic Incentives}

\section{Use of Structural Equation Modeling}

Unlike the level of adoption of HACCP, which can be decided upon a careful investigation into the respective records and through an on-site inspection, an analyst works on quantifying the real impact of an individual incentive on a behavior of firm faces several challenges, including: (a) "Mutual Exclusivity" and "Endogeneity" of incentives, i.e. prevalence of an individual incentive as an element of a system (Nakamura et al., 2001, Shavell, 1987); (b) "Subjectivity", i.e. the management of firm perceives these incentives in terms of potential benefits and costs to the firm (Buchanan, 1969), and (c) "Unobservability", i.e. the management cannot directly observe the nature of incentives prevailing at the firm level (Hair et al., 1998). 
To minimize such effects, and in turn, to come up with an objective assessment of individual incentives, moving beyond the methodology adopted by Jayasinghe-Mudalige and Henson (2006; 2007), this study has resolved to use the Structural Equation Modelling (SEM) with the aid of Analysis of Moment Structures (AMOS) [version 16] statistical package to quantify the effect of these incentives. SEM is a family of statistical models that seek to explain the relationships among multiple variables, which combines Measurement Model [commonly referred to as Confirmatory Factor Analysis (CFA)] and Structural Model into a simultaneous statistical test. It has the ability to incorporate latent variables (i.e. a hypothesized and unobserved concept such as "incentives" considered in this analysis) that can only be approximated by observable or measured variables or indicators into the analysis (Hair et al., 1998; Hoe, 2008). The models were developed and tested using SEM in Analysis of Moment Structures (AMOS) version 16 using Maximum Likelihood Estimation (MLE).

\section{Specification of Measurement Model}

The Measurement Model of SEM developed for the purpose of quantifying the individual economic incentives listed above is illustrated in Figure 01, where the nine incentives were served as the "Constructs" in the model with each loading on to five "Indicators", and as will be explained later, a series of attitudinal statements can be used to represent the Indicators of the model.

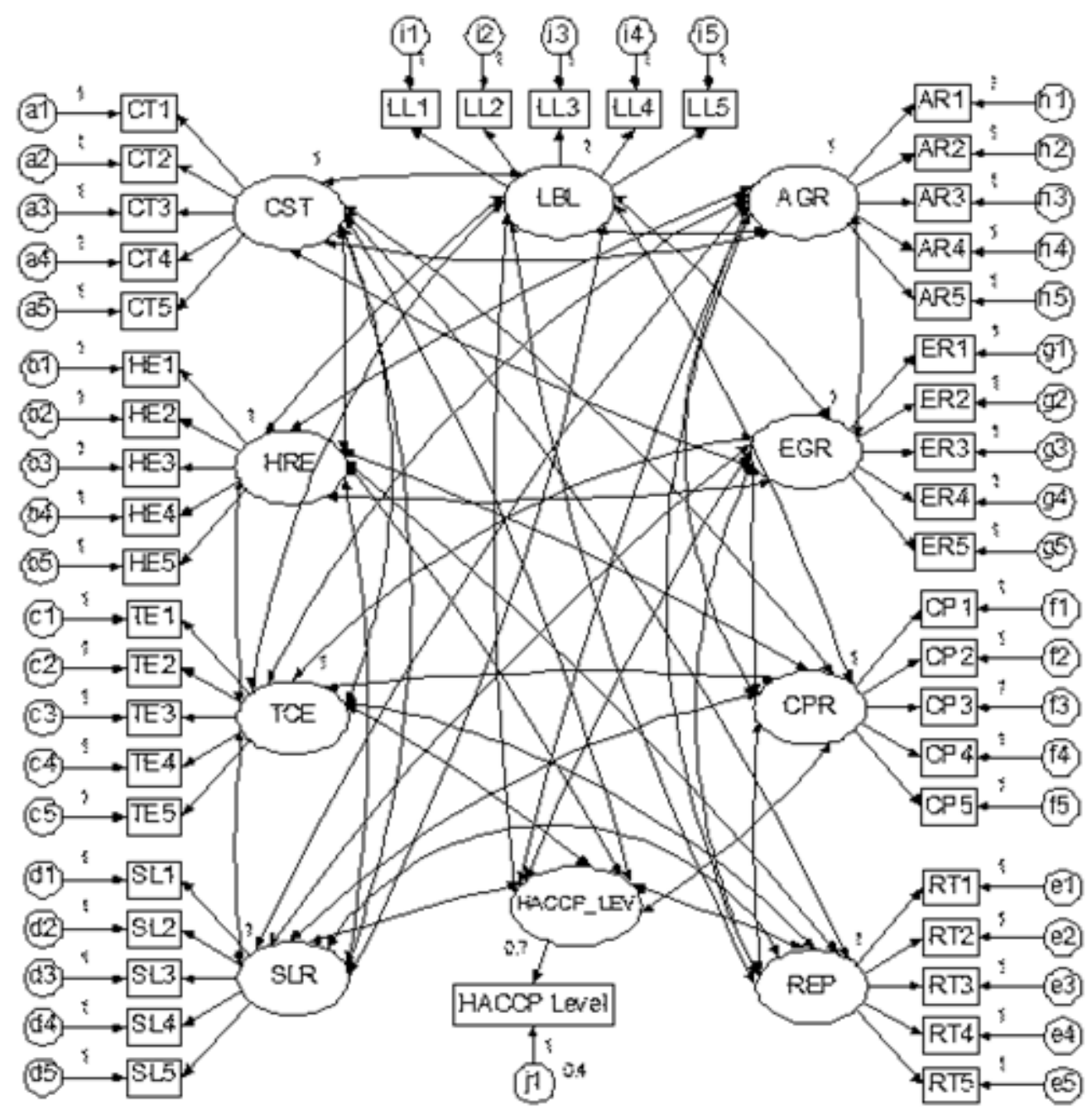

Figure 01: Measurement Theory Model for Confirmatory Factor Analysis 
Using the standard notations given in the Jöreskog and Sörbom (2001) and Hair et al. (1998), the Measurement Model can be expressed as follows by means of a series of equations such that for any single Indicator associated with an exogenous latent construct:

$\mathrm{x}_{1}=\lambda_{\mathrm{x} 1,1} \xi_{1}+\delta_{1}$

where, $\lambda_{x l, 1}$ represents the relationship between the latent factor $\xi_{1}$ and the measured variable $x_{1}$. The term $\delta_{1}$ represents the error. The recommendations of Hair et al., (1998) were considered to assess the validity of Measurement Model for its "Model Fit" and the "Construct Validity". The former was determined using Multiple Fit Indices. A number of other measures were employed to assess the Construct Validity, including: (a) "Face Validity" (content and meaning of the attitudinal statements representing Indicators in relation to their associated incentives); (b) "Convergent Validity" (indicators of a specific incentive should converge or share a high proportion of variance in common); (c) "Discriminant Validity" (extent to which a incentive is truly distinct from other incentives) and, (d) "Nomological Validity" (whether the correlations among the incentives in the measurement theory made sense) (Hair et al., 1998).

In addition, several other measures were estimated for the same purpose, including: (a) Factor Loadings (given as Regression Weights in the AMOS); (b) Reliability, and (c) Average Variance Extracted (AVE). With regard to Factor Loadings, Hair et al. (1998) recommend that Standardised Regression Weights obtained through the AMOS should be 0.5 or higher, ideally 0.7 or higher and at a minimum statistically significant. To test for Reliability, we have resolved to estimate the Construct Reliability (CR) using the Equation (2), as it is recommended to be used in conjunction with the SEM for this purpose (Garver and Mentzer, 1999):
$\mathrm{CR}=\left(\Sigma \lambda_{\mathrm{j}}\right)^{2} /\left(\Sigma \lambda_{\mathrm{j}}\right)^{2}+\Sigma\left(1-\lambda_{\mathrm{j}}^{2}\right)$

Where, $\lambda$ denotes the Standardized Factor Loading and $j$ shows the number of Indicators used in the model. The rule of thumb for CR is that it should be 0.6 or higher, and ideally 0.7 or higher to mean that reliability is good with internal consistency (Fornell and Bookstein, 1982). Based on the same notations, AVE can be estimated using the expression $\Sigma \lambda_{i}^{2} / \mathrm{n}$ (Hair et al., 1998), and a value of 0.5 or higher to which suggests adequate convergence and that the scale has higher distinct validity (Fornell and Larker, 1981).

\section{Specification of Structural Model}

Once the Measurement Model was established, the next step was to explore the Structural Model. Using the standard notations in Jöreskog \& Sörbom (2001) and Hughes et al. (1986), it can, theoretically, be expressed as in equation (3) below:

$\eta=\Gamma \xi+\zeta$

where, $\eta$ represents the endogenous construct in the model, $\Gamma$ is the corresponding matrix of parameter coefficients linking the exogenous constructs, $\xi$, with $\eta$ and $\zeta$ represents the error in the prediction of $\eta$. In AMOS, the nine individual incentives identified above were specified as exogenous constructs and the level of adoption of HACCP (HACCP_LEV) as the endogenous construct for this purpose (Figure 02).

The level of adoption of HACCP by a firm was treated as a "single-item measure" (see, Hair et al., 1998), and in turn, the best possible value for the Reliability was estimated (Est R). The relationship between the "actual level of HACCP adoption" variable (HACCP LEVEL) and the "latent construct" (HACCP_LEV) was then fixed to the square root of the estimated reliability and the corresponding error term was in consequently set to $=1-$ Est_R. 


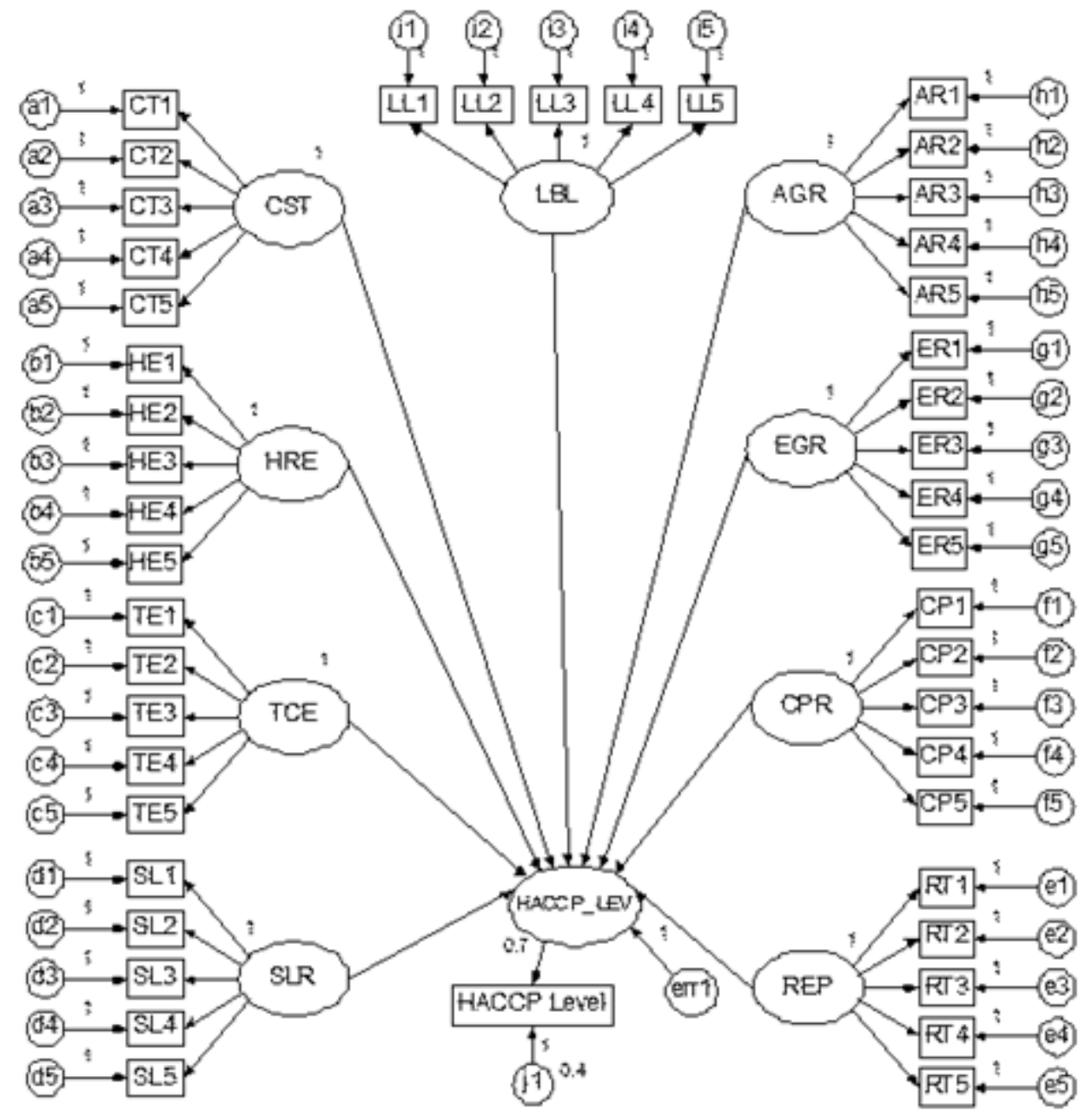

Figure 02: Structural Model for Estimated Structural Theory

Empirically, the single indicator of this construct consisted of binary response, i.e. whether the firm had an HACCP system at present or not. The outcome of this model was herein utilized to choose the set of indicators that most accurately reflect variation in the incentive they stand for. The management of firm can, in turn, evaluate the performance of her firm with regard to the phenomenon explained by each Indicator, which, evidently, represents an important characteristics of a given incentive (Henson and Traill, 2000; Jayasinghe-Mudalige and Henson, 2007).

\section{Derivation of an Incentive Related Index}

Once the most valid and reliable Indicators for the respective Constructs (i.e. attitudinal statements for incentives) were chosen, the next step was characterized by derivation of an index to reflect the relative effect of each incentive at the level of firm towards its action on adoption of HACCP, which is herein referred to as "Incentive Related Index" (IRI). This can be computed for each of the nine incentives using the scores given by respondents to each indicator. The IRI was, in particular, developed in the following manner:

$$
I R I_{i k}=\frac{\left(\sum X_{i j} / N_{k}\right)}{M}
$$

Where,

IRI $_{i \mathrm{k}}=$ Incentive related index of $\mathrm{k}^{\text {th }}$ incentive for the $\mathrm{i}^{\text {th }}$ respondent

$\mathrm{X}_{\mathrm{ij}}=$ Scores given by $\mathrm{i}^{\text {th }}$ respondent to $\mathrm{j}^{\text {th }}$ statement (of $\mathrm{k}^{\text {th }}$ incentive) 
$\mathrm{N}_{\mathrm{k}} \quad=$ Number of statements per $\mathrm{k}^{\text {th }}$ incentive

$\mathrm{M}$ =Maximum Potential Score for all statements of $\mathrm{k}^{\text {th }}$ incentive

The value of IRI, therefore, ranges from -1 to +1 depends on the scores provided by respondents to respective statements of an incentive on a multi-point likert-scale.

\section{Study Area and Data}

A face-to-face interview with the manager responsible for food safety and quality assurance/ owner of the firm of tea $(n=32)$ and dairy (n $=34$ ) processing firms from six provinces in Sri Lanka (Western, North Western, Central, North Central, Sabaragamuwa and Southern) were carried out between March and August 2009 with the support of a pre-tested $(n=8)$ structured questionnaire to collect data along with a site inspection and a search for records to verify the status of adoption of HACCP. For preparing the sampling framework, we obtained the mailing lists of food processing firms that operate at various locations by contacting reputed institutions such as: (a) the Department of Census \& Statistics of Sri Lanka; (b) the main and regional offices of the Export Development Board of Sri Lanka; (c) the Ministry of Industrial Development; (d) the Federation and Regional Chambers of Industry and Commerce; (e) National Agribusiness Council of Sri Lanka, and (f) Sri Lanka Standards Institution.

Our sampling frame was then created by crosschecking these addresses and identifying a master list of firms based on information provided by these various institutions. Any firm was considered for being included in the sample on the condition that it is willing to participate to the second stage of study too to facilitate the panel data analysis in future. Though this led to "non-participation" of some of the firms into the study in the first place, and as a result, the sample size became relatively small, we can generalize the outcome of analysis as the firms responded to the study embodied the general characteristics of the firms in these two industries.

To develop the Measurement Model, following Henson and Traill (2000) and JayasingheMudalige and Henson (2006), the responses to a set of attitudinal statements $(\mathrm{m}=45)$ in the questionnaire were defined as Indicators to reflect the observable characteristics of the nine incentives of interest. These statements were developed by the authors from the exploratory qualitative study, discussed in JayasingheMudalige and Henson (2007), following the recommendations of Zikmund (2003), Churchill (1979) and Zechmeister et al., (2009).

A series of in-depth interviews and group discussions were held with managers of food processing firms, industry experts (industry associations), and academics in the field of food science, food safety, agricultural economics, to review the attitudinal statements and determine the face validity. Based on the comments from these sessions, the attitudinal statements were finalized. The statements were a modification to the existing five-point likert scale, by including a "Yes" (Agree) and "No" (Disagree) field; resulting in a 1 to 5 range of 'agree a bit' to 'strongly agree' and 'disagree a bit' to 'strongly disagree'. This enabled the possibility of obtaining numerical scores that ranged from -5 to +5 to a statement on which the respondents were asked to score on based on its conceptual meaning and the underlying or corresponding phenomenon. Certain statement were inverted purposely in the questionnaire, so that respondents cannot guess the potential incentive, and in turn, provide answers invariably and hastily, thus preventing 'agreement bias'.

To assess the impact of firm characteristics on its behavior on food safety and quality assurance, the tea and dairy firms in the sample were categorized into four based on their size as follows: (1) Tea-Small (TS); (2) Tea-Large (TL); (3) Dairy-Small (DS), and (4) Dairy-Large (DL). Given empirical issues, 
we have resolved to use two different criteria to distinguish small firms from large firms in tea and dairy processing industries, where any tea processing firm of which green leaf intake per day was less (more) than $10,000 \mathrm{~kg}$ was considered a Tea-Small (Tea-Large) firm. For dairy, we cannot obtain a reliable measure on production applicable to all in the sample, given the lack of maintenance of proper records and/ or due to the issues related to "confidentially", thus, any dairy processing firm which possesses less (more) than 50 workers was considered a Dairy-Small (Dairy-large) firm. In addition, a further categorization similar to above was done on the level of HACCP adoption. Firms that already possess a system of HACCP were named as "HACCP Adopters" (HA) and the rest into "HACCP Non-adopters" (NA) to make the statistical analysis uncomplicated and to harmonize with small sample size.

\section{RESULTS AND DISCUSSION}

\section{Firms' Level of Adoption of HACCP}

The sample comprised of 32 tea and 34 dairy processing firms as reported in Table 01 . Nearly $31.3 \%$ of tea processing firms already possess a system of HACCP in the firm compared to just $20.6 \%$ of dairy processing firms. Also, we found that only $9.4 \%$ of tea processing firms have no plan to implement HACCP as compared to $64.7 \%$ of dairy processing firms in the sample. When this is considered with regard to the sizebased categories, as shown in Figure 03, almost all of the small diary (DS) firms have no plan to implement HACCP, while $22.2 \%$ of small tea (TS) firms, on the other hand, already have implemented HACCP with only $16.7 \%$ with no plan to implement. Even among the largesized firms, about $38.8 \%$ and $0.0 \%$ of large dairy (DL) and large tea (TL) firms were with no plan. These results are symptomatic that tea processing firms than the dairy processing firms and large firms than the small firms have greater propensity to adopt HACCP.

\section{Outcome of the Estimates of SEM from the AMOS}

As the first step towards quantification of incentives using the AMOS, the Measurement Model Fit was assessed by means of Multiple Fit Indices commonly used in this statistical package, namely Chi-square, CFI, TLI, and RMSEA (Hair et al., 1998; Hoe, 2008). However, the outcome of analysis at this point of time, which uses 45 statements as Indicators, indicated that the model fit was insufficient to proceed with the same set of indicators; thus, it needs to "prune" the superfluous Indicators. To do so, the Regression Weights (i.e. Factor Loadings) of each of the indicators were taken into account, and they were checked for the cutoff point of 0.5 or higher. We found that 13 out of the 45 statements had Standardized Regression Weights below the 0.5 cut-off point and 10 out of these were insignificant (at $\mathrm{p}=0.10$ ). As a result, the model was pruned by removing these 10 insignificant statements; however the remaining 3 statements were retained despite their low factor loadings because of their conceptual importance to their respective constructs, or in other words, to explain the specific facet of the corresponding incentive. Having removed the insignificant Indicators, the revised model was estimated again and the outcome of which is reported in Table 02.

The values of Measurement Model Fit Indices of the modified model indicated a reasonable model fit given the nature of the study in assessing a complex model through a relatively smaller sample size (Hair et al., 1998) and utilizing a 'total disaggregation' approach (Hoe, 2008). The Standardised Regression Weights indicated that all loadings were significant (at $\mathrm{p}=0.05$ ) and, except the 3 retained indicators, had the loadings exceeding 0.5 with more than half of the statements having the loadings above 0.7. The Construct Reliability (CR) and Average Variance Extracted (AVE) measures were estimated next for the modified version of model with 35 Indicators (Table 03). 
Table 01: Characteristics of firms in the sample

\begin{tabular}{llll}
\hline \multirow{2}{*}{ Sector } & \multicolumn{2}{c}{ Scale of Operation } & \\
\cline { 2 - 3 } & \multicolumn{1}{c}{ Small } & \multicolumn{1}{c}{ Large } & Total \\
\hline Tea & $<10,000 \mathrm{~kg}^{a}$ & $>10,000 \mathrm{~kg}^{a}$ & \\
& $18(27 \%)$ & $14(21 \%)$ & $32(48 \%)$ \\
Dairy & $<50 \mathrm{emp}^{b}$ & $>50 \mathrm{emp}^{b}$ & \\
& $16(24 \%)$ & $18(27 \%)$ & $34(52 \%)$ \\
Total & $34(58 \%)$ & $32(48 \%)$ & $66(100 \%)$ \\
\hline
\end{tabular}

Note: ${ }^{a}$ green leaf intake per day; ${ }^{b} \mathrm{emp}-$ no. of employees

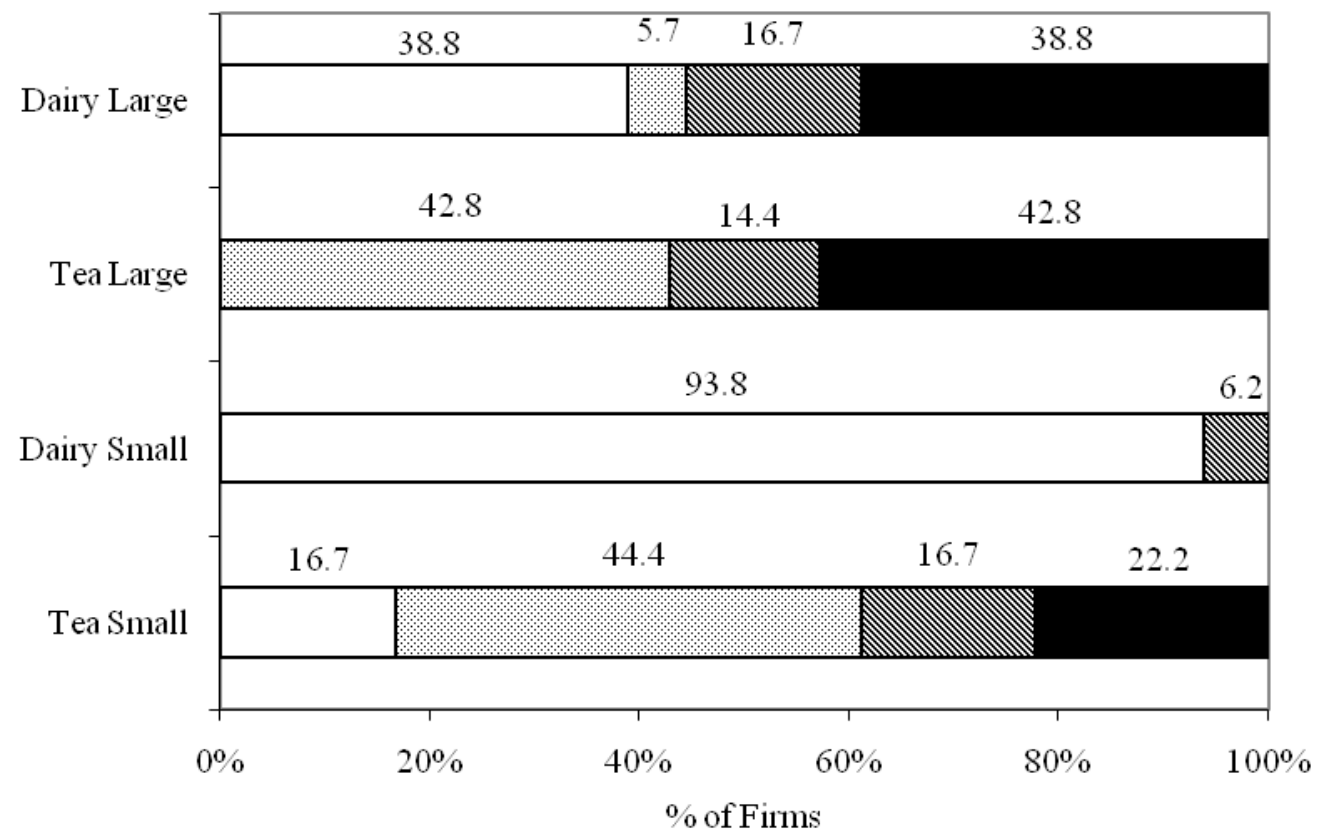

$\square$ No plans to implement $\quad 0$ Plans to implement $\mathbb{Q}$ Process of implementing

Have HACCP

Figure 03: Level of adoption of HACCP by tea and dairy firms

Table 02: Measurement and Structural Model Fit Indices

\begin{tabular}{cccc}
\hline Goodness-of-Fit Measures & $\begin{array}{c}\text { Measurement } \\
\text { Model Estimates }\end{array}$ & $\begin{array}{c}\text { Structural } \\
\text { Model Estimates }\end{array}$ & $\begin{array}{c}\text { Cut-off Values Based } \\
\text { on Model Characteristics }\end{array}$ \\
\hline $\begin{array}{c}\text { Chi-square }\left(\mathrm{X}^{2}\right) \\
\text { Degrees of Freedom (df) }\end{array}$ & 1226.59 & 1579.49 & \\
Probability Level & 550 & 587 & Significant p-values \\
can be expected & $<3$ \\
X'df Ratio & 0.000 & 0.000 & $>0.92$ \\
CFI & 2.230 & 2.691 & $>0.92$ \\
TLI & 0.894 & 0.872 & $<0.08$ with CFI of $>0.92$ \\
RMSEA & 0.822 & 0.815 & 0.073 \\
\hline
\end{tabular}


Table 03: Construct Reliability and Average Variance Extracted Estimates

\begin{tabular}{cccc}
\hline $\begin{array}{c}\text { Construct } \\
\text { (Individual Incentive) }\end{array}$ & $\begin{array}{c}\text { Construct Reliability } \\
(\mathrm{CR})\end{array}$ & $\begin{array}{c}\text { Average } \\
\text { Variance Extract } \\
(\mathrm{AVE})\end{array}$ & $\begin{array}{c}\text { Final No. of } \\
\text { Indicators }\end{array}$ \\
\hline CST & 0.807 & 0.506 & 5 \\
HRE & 0.762 & 0.527 & 3 \\
TCE & 0.627 & 0.535 & 3 \\
SLR & 0.589 & 0.464 & 4 \\
REP & 0.867 & 0.592 & 5 \\
CPR & 0.726 & 0.508 & 4 \\
EGR & 0.715 & 0.509 & 3 \\
AGR & 0.891 & 0.632 & 5 \\
LBL & 0.592 & 0.635 & 3 \\
\hline
\end{tabular}

The CR values of all, except three constructs, i.e. technical efficiency (TCE), sales and revenue (SLR) and liability (LBL), were above 0.7 with two constructs lower than 0.6. The CR estimates of SLR and LBL were only marginally below 0.6 , thus signifying that all constructs have adequate reliability. The AVE of only one construct fell below 0.5 (SLR) with all others having estimates above 0.5 . For all nine constructs as a whole, the indicators were sufficient in terms of Measurement Model specification. Satisfaction of conditions for all three estimates, i.e. Regression Weights, $\mathrm{CR}$ and AVE, thus, supported the Convergent Validity of the measurement model.

An examination of the Construct Correlation Matrix showed that none of the correlations exceeded 0.7 supporting adequate Discriminant
Validity and all, except human resource efficiency (HRE), had a positive relationship with other constructs. Although the behaviour of the other constructs showed sufficient Nomological Validity, the correlation values of HRE was unexpected. The estimates of AVE of all constructs (i.e. nine incentives) exceeded their corresponding Inter-construct Squared Correlation estimates. Overall, these measures supported the Discriminant Validity of the Measurement Model. In abstract, the Confirmatory Factor Analysis techniques applied to the Measurement Model proved its validity by means of sufficient model fit and adequate Construct Validity. The Standardised Regression Weights of the hypothesised structural paths, or in other words, Standardised Path Coefficients, are illustrated in Table 04.

Table 04: Standardized regression weights for the structural paths

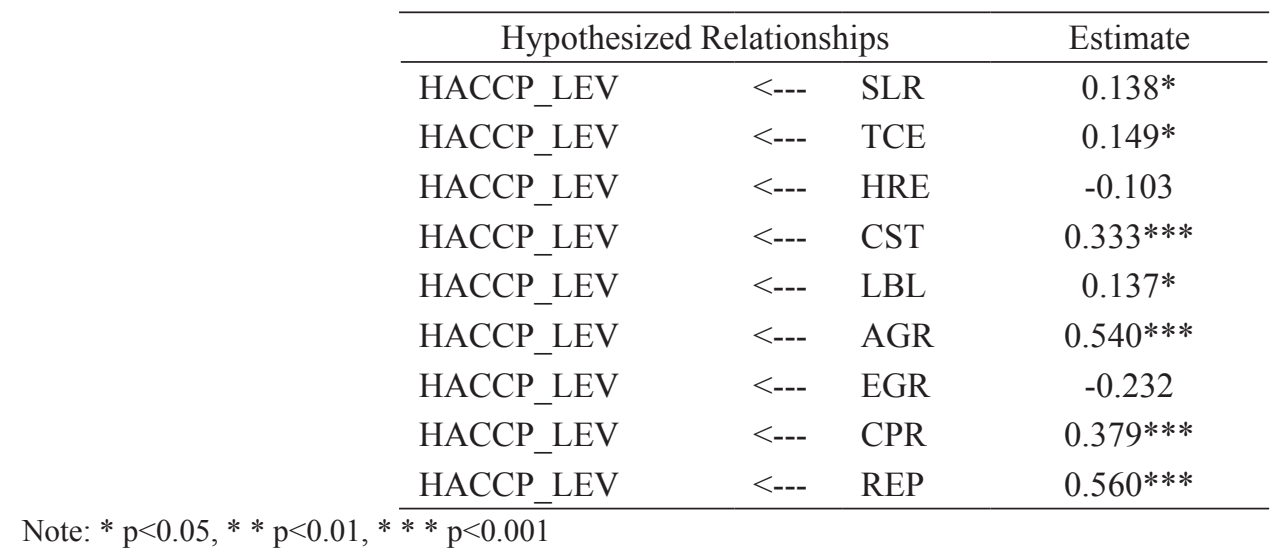


Chin (1998) recommends that standardised paths of a Structural Model should be at least 0.20 , and ideally above 0.30 , in order to be considered meaningful for discussion. Also, the estimates need to be statistically significant and in the predicted direction. Out of the nine hypothesised structural paths, only two were neither significant nor in the expected direction (i.e.HRE $\rightarrow$ HACCP_LEV and EGR $\rightarrow$ HACCP LEV). However, it was interesting to note that, given an insignificant path linking EGR and Level of HACCP adoption, the hypothesised relationship between AGR and HACCP adoption was both significant and carried a high path coefficient estimate.

Among the nine incentives, reputation (REP), anticipated government regulation (AGR), commercial pressure (CPR) and cost and financial implications (CST) were the most important determinants and motivators of firms' behaviour in relation to food safety and adoption of HACCP. Although sales and revenue (SLR), liability (LBL), and technical efficiency (TCE) had a positive and significant relationship with HACCP adoption, the low path coefficients, adds minimal value to the understanding of the relationships between these incentives and the adoption decision (Hoe, 2008). Also, the substantial support for the hypothesized relationship between CST and HACCP adoption was surprising, given the prior expectation of
CST being a deterrent for firms to implement food safety practices.

\section{Values of the Incentive Related Index}

The scores provided by respondents to each Indicator of an incentive on the five-point likert scale were, then, used to derive the IRI for each firm. Figure 04 illustrates the distribution of Mean IRI value (i.e. aggregate of the values of IRI / number of firms) for the firms that already have HACCP in the firm (HA), which, in particularly, belong to the sub-categories of "Small-Tea" (HA-TS), "Large-Tea" (HA-TL), and "Large-Dairy" (HA-DL).

Irrespective of the firm size and type, among the adopters of a system of HACCP, one of the most important incentives was Reputation (REP). This result was in-line with the supported relationship in the SEM phase. This suggests, perhaps that firms are more likely to implement enhanced food safety practices if they are more concerned with brand equity, as they perceive HACCP certification as an element of their corporate reputation, and believe that this improves the image of the enterprise in the market. Existing government regulation (EGR) followed Reputation as an important motivator for HACCP adoption. However, the lack of support from the SEM phase pushes to doubt the IRI indication.

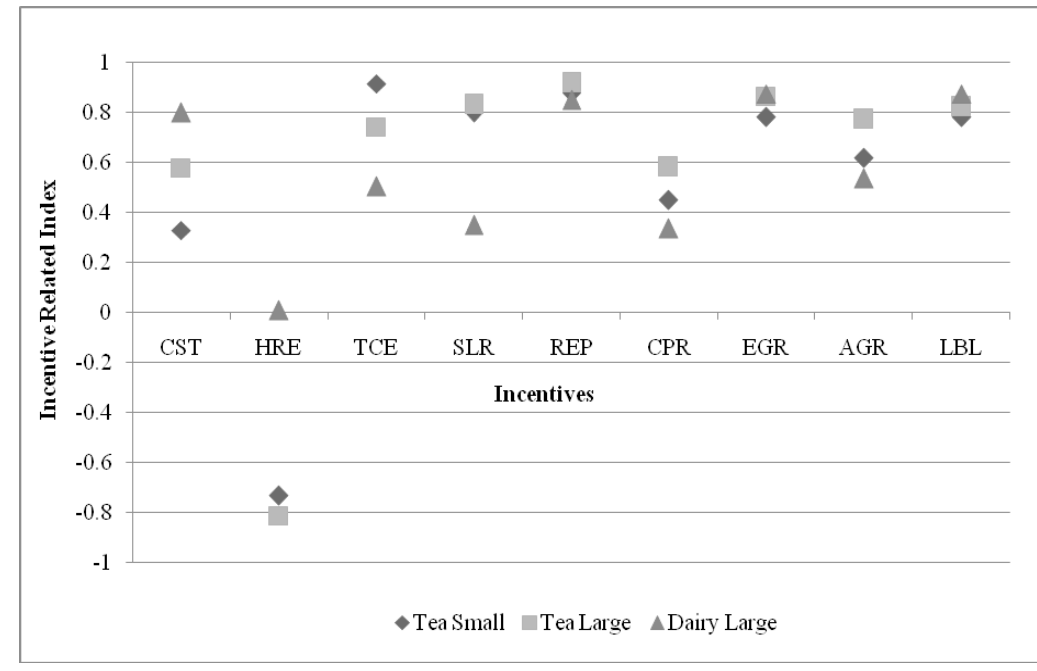

Figure 04. Mean Index Values for the adopters of HACCP 
Both large scale tea (HA-TL) and dairy (HADL) firms indicated that the effect of legal system and judiciary has pressurized them to behave food safety responsibly and the IRI pertaining to the Liability laws (LBL) was highest in the large scale dairy firms (HADL). The insinuated role of liability laws is reasonable; both tea and dairy processing firms perceive HACCP as a hedge, which reduces their liability should a consumer suffer food product related poisoning. This is clearly important for dairy processing plants, given that milk is a highly perishable commodity and a good microbial support media. In addition, larger firms are more sensitive to liability issues than smaller firms and perhaps are more aware of the negative impacts of liability cases against the company.

The Mean IRI of small and large scale tea firms (HA-TS and HA-TL) demonstrated Sales and revenue (SLR) as one of the predominant drivers of HACCP adoption in the firm. Tea processing firms are conceivably more concerned with issues such as revenue and market share since they predominantly trade in the export markets. The relatively lower Mean IRI for the individual incentives of Commercial pressure (CPR) and anticipated government regulation (AGR) came in stark contrast to priori expectations, given the strong support for the hypothesised relationship in the Structural Model. For both these incentives, both small and large scale tea processing firms (HA-TS and HA-TL) had larger values than large scale dairy (HADL). This is acceptable, considering that tea processing firms consider adoption of HACCP since it is a requirement of their international customers, while most of the dairy processing firms including HACCP adopters believed that a majority of their customers do not have any idea about HACCP.

In the dynamic global marketplace, tea processing plants may consider the need to prepare for changing regulatory systems and possible HACCP certification requirements in markets other than the European Union. Dairy firms on the other hand, and small firms in particular, who predominantly serve the local customer base do not anticipate any government regulation mandating HACCP adoption in the near future.

For all firms that have adopted HACCP, Cost/ financial implications (CST) were a considerable incentive. Further, the impact of this incentive was found to be increasing with increasing firm size. Firms that have implemented HACCP in their plants perceive it as cost efficient, with larger firms in a better position in both resources and capabilities to support enhanced food safety practices. The negative index values for Human resource efficiency (HRE) for almost all categories, together with the insignificant relationship in the structural model, imply that firms do not perceive HACCP adoption enhances efficiency of their human resources and thus is not a significant motivating factor.

\section{CONCLUSIONS \\ AND POLICY IMPLICATIONS}

The role and impact of firm level incentives comprised of an elements of a system of marketbased, regulatory and liability incentives to adopt HACCP food safety metasystem in the agri-food processing sector of Sri Lanka were assessed in this study with special reference to its tea and dairy processing firms. Overall, the results suggest that reputation is the most important propeller behind food safety responsive behaviour of firms, followed by sales and revenue as being more important for tea plants and liability laws having high impact on dairy firms. Other coercive elements responsible for the HACCP adoption behaviour were commercial pressure and anticipated government regulation.

Outcome of the analysis, overall, calls for better recognition of market-based incentives from policy makers and demand for an approach in the 
form of "Carrot (to comply) and Stick" (for noncompliance), as suggested by Segerson (1999), to augment the levels of food safety maintained by the firms, since both market and regulatory incentives operate side-by-side in a complex and close association; not only rely on one form of incentives, but utilize both to enhance the food safety aspects of the agri-food processing sector. Support programmes to improve brand equity, assistance to branding exercises and quality/ safety certification, subsidised communication and promotional channels/options, properly functioning liability system, publicity for liability cases or food product-related trials, increasing public awareness about safety and quality issues, and step-wise directives on food safety metasystems, are some of the areas that could be addressed by policies and action programmes to augment firms responsiveness towards food safety, in turn.

The results also highlight the importance of workings of the private (market) and public (non-market) institutions to enhance the levels of food safety maintained by firms on a more "dynamic" perspective, i.e. by taking into account of changes to the incentive-base of a firm over time, to make sure such efforts are sustainable and cost-effective, as the firms responsiveness to food safety depend largely on concurrent changes in the business environments, both locally and globally. The implications of this study is, therefore, such that it provides justification for designing a system that guarantee the consumers of a safe food supply while avoiding draconian measures that hamper the competitiveness of food businesses by curtailing the incentives for producers with little marginal benefit from improved safety controls, or in abstract, there is room for development of an incentive-based regulatory framework for tea and dairy processing sector, in particular, and the agri-food processing sector in Sri Lanka, in general, to augment food safety at the level of firm.

\section{ACKNOWLEDGEMENTS}

The authors would like to express their sincere gratitude to the "National Science Foundation of Sri Lanka" for providing financial assistance to carry out this two-stage program of research under its Competitive Research Grant RG/2008/ $\mathrm{AG} / 05$. Also, a special thank is due to Mr. K. P. N. G. Kanuwana, Ms. W. A. S. Wijesinghe and Ms. M. Katugampola for their generous support to complete the first phase of analysis.

\section{REFERENCES}

Buchanan J. M. (1969). Cost and choice: an inquiry in economic theory, Chicago: Markham. Publishing Co.

Bukenya J. O. and Nettles L. (2007). Perceptions and willingness to adopt Hazard Analysis Critical Control Point practices among goat producers. Review of Agricultural Economics, 29(2): 306-317.

Buzby J. C., Frenzen P. D. and Rasco B. (2001). Product liability and microbial food-borne illnesses. U.S. Department of Agriculture. Economic Research Service Agricultural Economics Report 799.

Caswell J. A., Bredahl M. E. and Hooker N. H. (1998). How quality management meta-systems are affecting food industry. Review of Agricultural Economics, 20: 547-557.

Chin W. W. (1998). Issues and opinion on structural equation modeling. MIS Quarterly, 22(1): 7-16. 
Churchill G. Jr. (1979). A paradigm for developing better measures of marketing constructs. Journal of Marketing Research, 16(1): 64-73.

Fornell C. and Bookstein F. L. (1982). Two structural equation models: LISREL and PLS applied to consumer exit-voice theory. Journal of Marketing Research, 19(4): 440-453.

Fornell C. and Larker D. F. (1981). Structural equation models with unobservable variable and measurement error: algebra and statistics. Journal of Marketing Research, 18(3): 382-388.

Garver M. S. and Mentzer J. T. (1999). Logistics research methods: employing structural equation modeling to test for construct validity. Journal of Business Logistics, 20(1): 33-57.

Hair J. F., Anderson R. E., Tatham R. L. and Black W. C. (1998). Multivariate Data Analysis. (5 Editioon). Prentice-Hall, New Jersey.

Henson S. and Northen J. (1998). Economic determinants of food safety controls in supply of retailer own-branded products in United Kingdom. Agribusiness, 14(2): 113-126.

Henson S. and Traill B. (2000). Measuring perceived performance of the food system and consumer food-related welfare. Journal of Agricultural Economics, 51(3): 388 - 404.

Henson S. and Holt G. (2000). Exploring incentives for the adoption of food safety controls: HACCP implementation in UK dairy sector. Review of Agricultural Economics, 22(2): $407-$ 420.

Henson S. and Hooker N. H. (2001). Private sector management of food safety: public regulation and the role of private controls. International Food and Agribusiness, 4(1): 7-17.

Henson S. (2007). The role of public and private standards in regulating international food markets. Journal of International Agricultural Trade and Development, 4(1): 52-66.

Henson S. and Jaffee S. (2008). Understanding developing country strategic responses to the enhancement of food safety standards. The World Economy, 31(1): 1-15.

Hoe S. L. (2008). Issues and procedures in adopting structural equation modeling technique. Journal of Applied Quantitative Methods, 3(1): 76-83.

Hughes M. A., Price R. L. and Marrs D. W. (1986). Linking theory construction and theory testing: models with multiple indicators of latent variables. Academy of Management Review, 11(1): 128-144.

Jayasinghe-Mudalige U. K. and Henson S. (2006). Economic incentives for firms to implement enhanced food safety controls: case of the Canadian red meat and poultry processing sector. Review of Agricultural Economics, 28(4): 494-514.

Jayasinghe-Mudalige U. K. and Henson S. (2007). Identifying economic incentives for Canadian red meat and poultry processing enterprises to adopt enhanced food safety controls. Food Control, 18(1): 1363-1371.

Jöreskog K. and Sörbom D. (2001). Lisrel 8: user's reference guide. (2 ${ }^{\text {nd }}$ Edition). Lincolnwood: Scientific Software International Inc. 
Mortimore S. and Wallace C. (1998). HACCP: A practical approach, Maryland: Aspen Publishers Inc.

Nakamura M., Takahashi T. and Vertinsky I. (2001). Why Japanese firms choose to certify: a study of managerial responses to environmental issues. Journal of Environmental Economics and Management, 42(1): 23-52.

Shavell S. (1987). Economic analysis of accident law. Cambridge: Harvard University Press.

Ollinger M. and Moore D. L., 2008. The economic forces driving food safety quality in meat and poultry. Review of Agricultural Economics, 30(2): 289-310.

Segerson K. (1999). Mandatory versus voluntary approaches to food safety. Agribusiness, 15(1): 53-70

Veeman M. (2000). Changing consumer demand for food regulations. Canadian Journal of Agricultural Economics, 47: 401-409.

Wu L., Xu L., Zhu D. and Wang X. (2012). Factors affecting consumer willingness to pay for certified traceable food in Jiangsu province, of China, Canadian Journal of Agricultural Economics, 60: 317-333.

Zechmeister J. S., Zechmeister E. B. and Shaughnessy J. J. (2009). Essentials of Research Methods in Psychology. New Delhi: Tata McGraw-Hill Education.

Zikmund W. G., (2003). Business Research Methods. $7^{\text {th }}$ Edition. New Delhi: Cengage Learning. 